\title{
Study on building efficient airspace through implementation of free route concept in the Manila FIR
}

\author{
Z. Xie*, S. Aneeka, Y. X. Lee, Z. W. Zhong \\ School of Mechanical and Aerospace Engineering, Nanyang Technological University, Republic of Singapore
}

\section{A RT ICLE INFO}

\section{Article history:}

Received 10 March 2017

Received in revised form

2 October 2017

Accepted 5 October 2017

\section{Keywords:}

Efficient airspace

MATLAB simulation

Free route

Route structure

Philippine FIR

\begin{abstract}
A B S T R A C T
The air traffic volumes in ASEAN region are expected to triple by 2030 based on forecasting results. The concept of Seamless ASEAN Sky has been raised to increase air capacity and efficiency in the region. The current airspace structure may not be capable of meeting the anticipated future air traffic demand. As a result, the authors applied free route airspace structure to accommodate more aircraft under Manila FIR. The methodology proposed in this paper can increase the airspace capacity while decreasing the ATCs workload by using free route airspace concept. A case study was carried out on Manila FIR to examine the effectiveness of this method.
\end{abstract}

(C) 2017 The Authors. Published by IASE. This is an open access article under the CC BY-NC-ND license (http://creativecommons.org/licenses/by-nc-nd/4.0/).

\section{Introduction}

With the growth of GDP and population, the air traffic demand grows rapidly in Southeast Asia especially in cities for example Kuala Lumpur, Jakarta, Singapore, and Bangkok (Xie and Zhong, 2016). Budget airlines are also one of the main factors which contribute to the fast increase of air traffic volumes due to cheap air tickets and point to point transit modes (Barrett, 2004). However, the current airspace and air route structures may not be capable of accommodating future air traffic. As a result, a comparative study on the current and new air route structures can help to identify benefits in terms of flight efficiency and route capacity. Such studies could be done on many Flight Information Regions (FIRs) in Southeast Asia.

Pappas et al. (1997) and Tomlin et al. (1996) proposed a decentralized Air Traffic Management (ATM) architecture to increase the safety and efficiency of airspace. Under the free flight concept, the pilots can decide the 4-dimensional routes instead of following discrete airspace structure. As a result, the useful airspace is expanded and airspace capacity is largely increased. Last but not least, the author proposed methods for the conflicts resolution in the decentralized ATM structure.

Han et al. (2006) designed a new airway parallel to the original single airway between Beijing and Shanghai to form the parallel navigation airway. Air

\footnotetext{
* Corresponding Author.

Email Address: ZXIE@ntu.edu.sg (Z.Xie)

https://doi.org/10.21833/ijaas.2017.012.003

2313-626X/C 2017 The Authors. Published by IASE.

This is an open access article under the CC BY-NC-ND license

(http://creativecommons.org/licenses/by-nc-nd/4.0/)
}

traffic control intervention is also studied by the author to assess the security of the proposed airspace structure. The results show that the structure is helpful for the improvement of sector airspace capacity.

Tomlin et al. (1996) and Pappas et al. (1997) designed hybrid control of the next generation ATM to allow the vehicle to switch flight mode and solve conflicts. The author found that fast time computers on board and in the control tower could help to build more advanced air traffic management systems. The autonomy of the aircraft could be increased if the aircraft avoids the ground-based air traffic control and the predefined airway fix points. The optimal path of the aircraft could also be planned based on the current situation.

Sunil et al. (2016) developed methods to establish the relationship between the structuring of traffic and the airspace capacity. Large scale simulation was used to compare four airspace concepts. The simulation showed that the traffic structure must include the traffic demand pattern in order to increase the future capacity. A decentralized layered airspace concept had the best performance in safety, efficiency, and stability.

In this paper, the authors consider the case of Manila FIR for the comparative study. Philippines had the largest index of projected population growth till 2050 among all the Southeast Asian countries according to the United Nations Medium Projection (DeSA, 2013). The air traffic volumes in the Philippines could be expected to grow significantly in the future. In this paper, the authors propose the implementation of free route concept to Manila FIR to accommodate future traffic demand. 
In this paper, the authors use the System for air traffic Assignment and Analysis at a Macroscopic level (SAAM) software developed by EUROCONTROL (2015) to display the route structure redesign results in comparison with the original route structure. Fig. 1 shows the Manila FIR air traffic data on one specific day by SAAM. The simulation in SAAM can give a macroscopic view of the air traffic and can be used to design airspace and route structure.

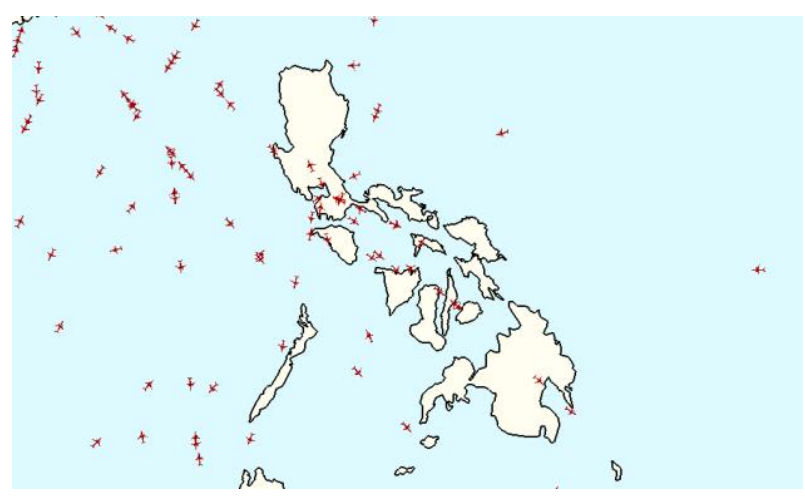

Fig. 1: Manila FIR air traffic simulation

Free flight concept emerged as a result of the development of advanced tracking, prediction and communication equipment (RTCA, 1995; Gibbs, 1995). Free flight can replace the rigid route structure which could in turn lead to more direct or wind-optimal trajectory (Paielli and Erzberger, 1997). Free flight improves the airspace efficiency and safety. Moreover, free flight is one of the key elements of the next generation ATM.

Free flight increases the safety operation of the flight especially in adverse weather conditions and congested airspace. Free flight also reduces the workload of the air traffic controllers (ATCs). The weather information and obstacle information can help pilots make the right decision to guide the aircraft safely.

The weather information for the aircraft given by the current ground stations is not real-time weather data and is always delayed. However, in the free flight scenarios, the equipment on board can detect the real-time environment information and provide suggestions to the pilots to avoid dangers.

Free Route Airspace was initiated among European member states by EUROCONTROL (2008). In free route airspace, users can plan a route from the entry point to the exit point, but the flight is still under the ATC (EUROCONTROL, 2008). Currently, 30 of 64 European ACCs have already fully or partially implemented free route. The ultimate goal is to create the Single European Sky (SES) (Hering, 2005).

Another key element for both free flight and free route is the automatic dependent surveillance broadcast (ADS-B) (Rekkas and Rees, 2008). ADS-B can replace the current secondary surveillance radar used in air traffic control (ATC). ADS-B can provide surrounding aircraft information and meteorological information in the airspace. The use of ADS-B can reduce the separation distance and increase the capacity of airspace.

In this paper, we assume that the free route concept has been already implemented in the Manila FIR. After that, analysis of the free route scenarios in the Manila FIR is conducted using SAAM software. In the end, we compare the airspace efficiency of free route structure with that of the current route structure. The results show that the free route structure can largely increase the airspace capacity and efficiency. This approach could be used to test the effectiveness of free route airspace concept in other ASEAN FIRs.

\section{Methodology}

\subsection{Manila FIR}

As shown in Fig. 2, the light blue block represents the Manila Flight Information Region (FIR). In this study, we only focus on the route structure redesign in the Manila FIR. The route structures in other FIRs can be improved in the same procedures by this method as well.

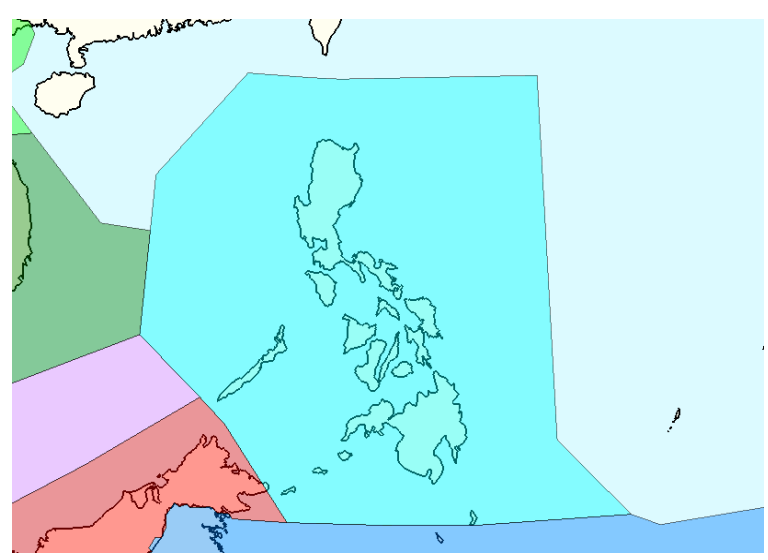

Fig. 2: Manila FIR

\subsection{Current route structure}

Fig. 3 shows the current route structure in Manila FIR. The priority must be given to the busiest city pairs. In Manila FIR, the busiest city pairs are Manila and Cebu. In ASEAN FIRs, the busiest city pairs with Manila FIR are Manila - Singapore, and Manila - Hong Kong. In this paper, we only talk about the airspace in Manila FIR. As the number of aircraft increases, Manila-Cebu airways would encounter the highest traffic volumes. As a result, the design of a new airspace route structure would benefit air traffic between Manila and Cebu significantly. We apply free route concept on Manila FIR to improve the current route structure and enhance the airspace capacity. Free route could also increase the capacity as it can use more airspace than the current discrete route structure.

Fig. 4 shows the entry rate for this specific day in the Manila FIR. The total number of aircraft is 1,245. We can find that the entry rate reaches its highest level around 0200 to 0500 UTC at around 80 flights. After that, the entry rate decreases slowly until 1500 
UTC at around 20 flights. From 1500UTC onwards, the entry rate starts to go up until the next day. Thus, the airspace experiences high workload at around 0200 UTC to 0800 UTC while lesser flights are observed at around 1500 UTC to 2200 UTC.

\subsection{Assumptions}

In order to simplify the scenario, we have the following assumptions.

1) There are no restricted areas in Manila FIR. As a result, the whole FIR is accessible to any aircraft in our simulation.

2) Free route is already approved and achieved in Manila FIR.

3) In the case of conflicts, air traffic controllers separate conflict flight to keep a safe distance. Then, the pilots start to deviate the aircraft vertically or horizontally.

4) We only consider the en route flight from flight level 16 to flight level 600.
5) Free route is created by straight airway but under control of ATCs.

6) The available flight levels in Manila FIR are FL260, FL300, FL330, FL370, FL410 and FL460.

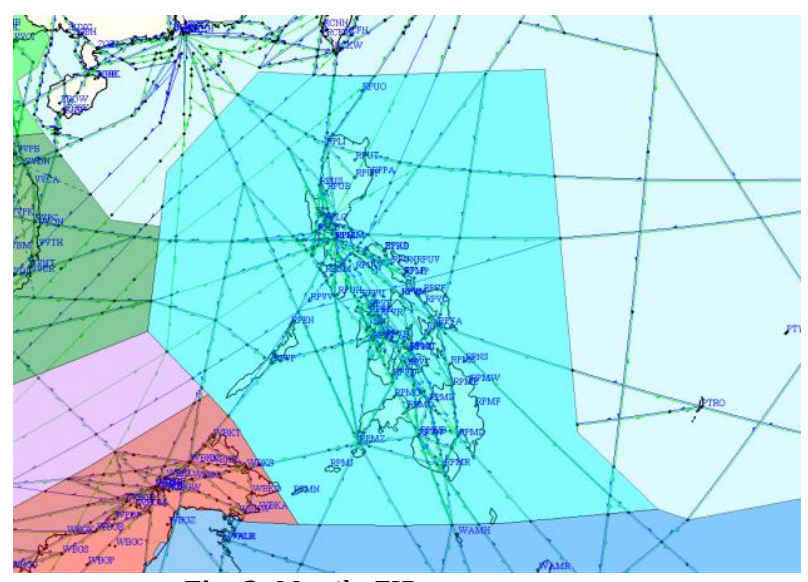

Fig. 3: Manila FIR route structure

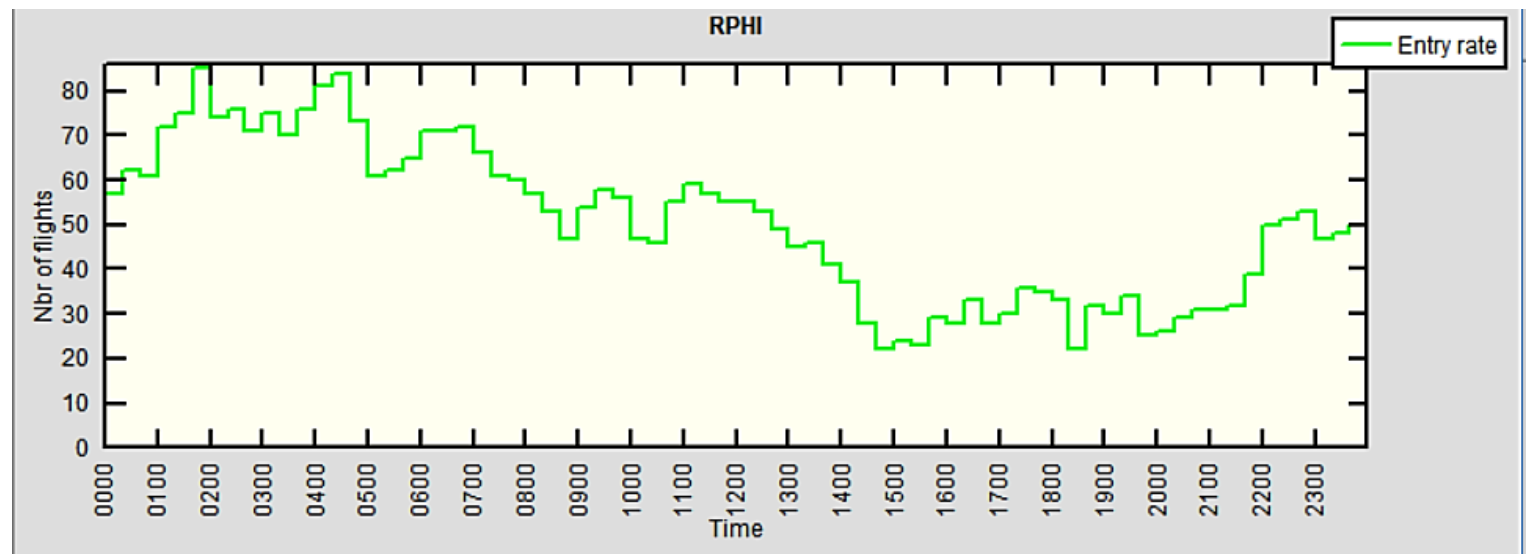

Fig. 4: Airspace load

\subsection{Conflict resolution}

The horizontal separation is at least 5 nautical miles as shown in Eq. 1. In usual operations, the minimum vertical separation is $2000 \mathrm{ft}$ above 29000 $\mathrm{ft}$ and $1000 \mathrm{ft}$ below 29000ft (Bicchi and Pallottino, 2000). In this paper, the vertical separation is fixed at $2000 \mathrm{ft}$ as seen in Eq. 2. The conflicts of two aircraft can be divided into cross track, head to head and run after. The pilots guide the aircraft horizontally with a minimum $5 \mathrm{nmi}$ separation or $2000 \mathrm{ft}$ separation vertically in order to avoid the conflicts.

$D_{\text {horizontal }}>5 \mathrm{nmi}$

$D_{\text {vertical }}>2000 \mathrm{ft}$

\section{5. $A^{*}$ search algorithm}

In the less dense flight airspace, free route zone can be achieved (Hering, 2005). Despite the fact that pilots could guide the vehicle freely, a reference route was also shown to the pilot in the onboard computer generated by algorithms. Here, we used the $A^{*}$ search algorithm (Hart et al., 1968) to find the optimal path with obstacle collision. However, the pilots can drive different paths based on their own intentions as long as the aircraft is safe from minimum separation and adverse weather (Xie and Zhong, 2016).

The optimal function we use here is demonstrated in Eq. 3.

$F(n)=H(n)+G(n)+A(n)+D(n)$

F (n) stands for the objective function;

$\mathrm{H}$ (n) stands for the estimated cost from the current position to the final position;

$\mathrm{G}$ (n) stands for the cost for reaching the current position from the start position;

A ( $n$ ) is the turning angle of the aircraft;

$\mathrm{D}(\mathrm{n})$ is the route deviation from the reference route.

Fig. 5 shows one example of the reference route generated by $A^{*}$ search algorithm which can avoid the adverse weather and keep the safe separation from other aircraft. The red dots represent aircraft using the same airspace which causes the conflicts. The squares represent the adverse weather and the restricted areas. The pilots can use this route as a 
reference to decide which route to take in order to create safe and efficient flights.

\subsection{Free route simulation}

The free route simulation is done in SAAM. As seen in Fig. 6, in free route airspace, entry points and exit points are linked with straight routes (EUROCONTROL, 2008).

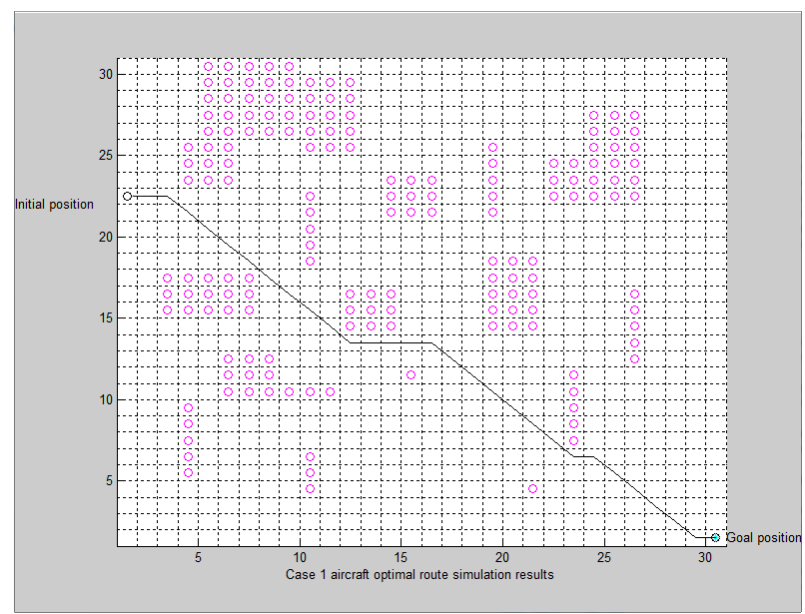

Fig. 5: Safe reference route example

This route structure can greatly shorten the route distance and travel time. Moreover, the free route can also decrease the fuel consumptions and gas emissions which can benefit the environment. A comparison between free route structure and current airspace structure is done in the next section.

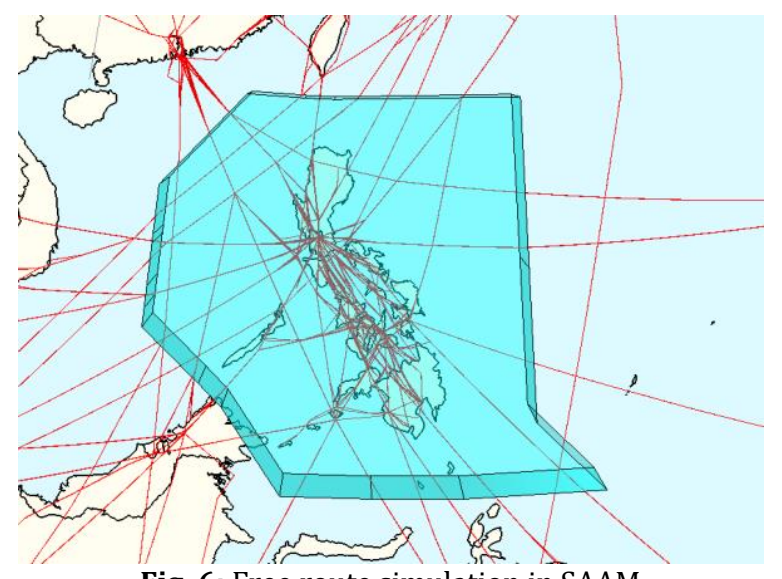

Fig. 6: Free route simulation in SAAM

\section{Results and discussion}

\subsection{Comparison between free route and current route structures}

As shown in Fig. 7, the purple line shows the free route airspace structure while the green line shows the original route structure. The graph clearly shows that free route structures are simpler and more direct than the current discrete route structure.



Fig. 7: Free route compare with current route structure

\subsection{Environment benefit}

The environmental benefit for the free route is obvious. The number of flights which is impacted by the implementation of free route is 1,137 as seen in Table 1. The total saving length and saving flight time by the implementation of free route are $16,417.66 \mathrm{nmi}$ and 2,204.27 mins respectively. Besides this, Table 1 also demonstrates the environment benefits for the free route airspace. With Free Route implementation in the Manila FIR, the fuel consumption can be saved up to $121,457.61$ $\mathrm{kg}$ when compared to the current route structure. As a result, $\mathrm{CO}_{2}$ emissions and $\mathrm{NOx}$ emissions would decrease by about $383,810.244 \mathrm{~kg}$ and $1,761.62 \mathrm{~kg}$ respectively. This significant saving in fuel not only reduces expenses for the airlines but can also help to reduce impacts of climate change.

Table 1: Environment for free route

\begin{tabular}{cccccc}
\hline \multicolumn{6}{c}{ Scenario Economy for free route airspace (Potential gains/losses) } \\
\hline $\begin{array}{c}\text { Total } \\
\text { impacted } \\
\text { flights }\end{array}$ & $\begin{array}{c}\text { Length } \\
\text { (NM) }\end{array}$ & $\begin{array}{c}\text { Time } \\
(\mathrm{min})\end{array}$ & $\begin{array}{c}\text { Fuel } \\
(\mathrm{kg})\end{array}$ & $\begin{array}{c}\text { CO2 } \\
(\mathrm{kg})\end{array}$ & $\begin{array}{c}\text { NOx } \\
(\mathrm{kg})\end{array}$ \\
1137 & 16418 & 2204 & 121458 & 383810 & 1762 \\
\hline
\end{tabular}

\subsection{Capacity improvement}

Under the current separation rules, for the en route aircraft, the horizontal separation is $5 \mathrm{nmi}$. If the separation rules stay the same, the airspace could accommodate more aircraft in the free route scenarios. Due to the utilization of more airspace, the possible routes which link the entry points and exit points could be decided by pilots. Instead of following the discrete waypoints in the current airspace structure or instead of following the straight lines, all the potential routes can be taken as long as there is no collision or invasion of restricted areas.

\subsection{Workload improvement}

The workload for the air traffic control officers (ATCOs) decreased as a result of the free route structure. As we can see in Fig. 8, the schematic diagram shows that the workload for the Executive 
Controllers (ECs) in free route scenarios is around $21.8 \%$ lesser than that of the current airspace structure. Fig. 9 illustrates that free route has reduced the workload of the Planning Controller for around $43.1 \%$. Overall, the workload for both the executive ECs and PCs has decreased. The relief of the ATCs workload can contribute to higher safety operation level of air traffic control and let ATCs be capable of handling more aircraft.

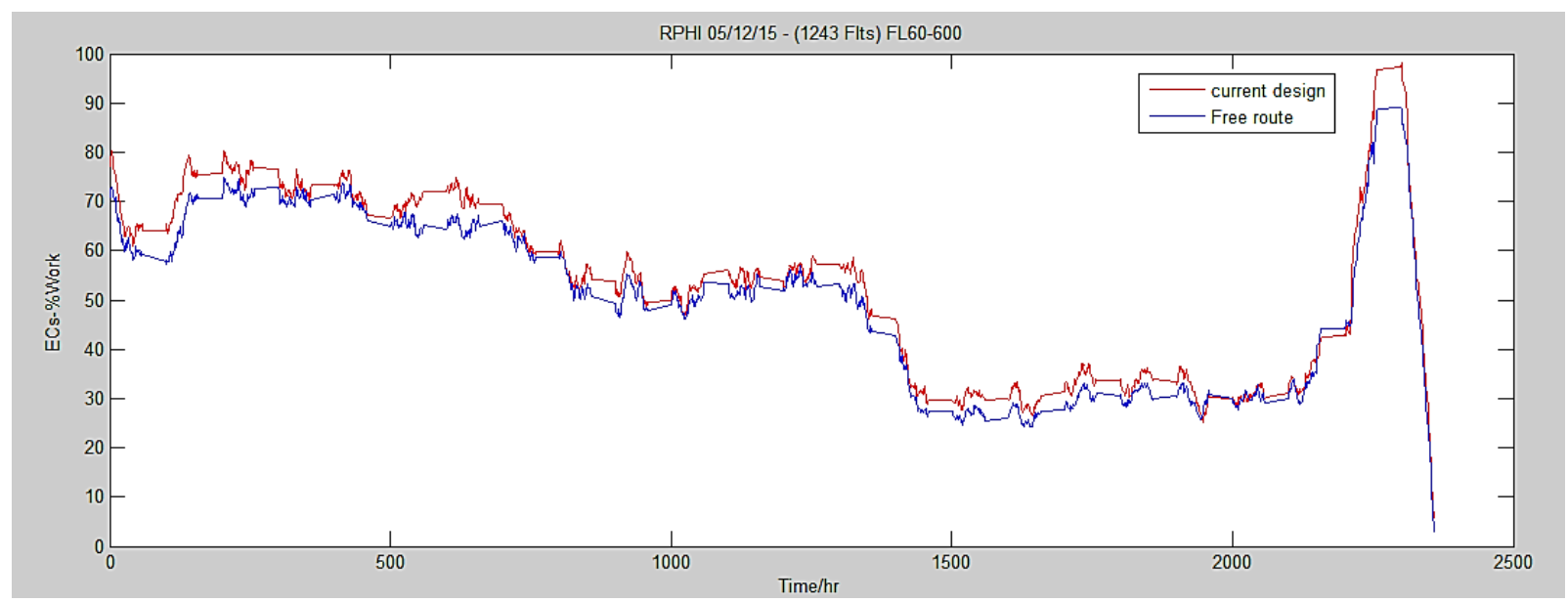

Fig. 8: Executive controller's workload relief

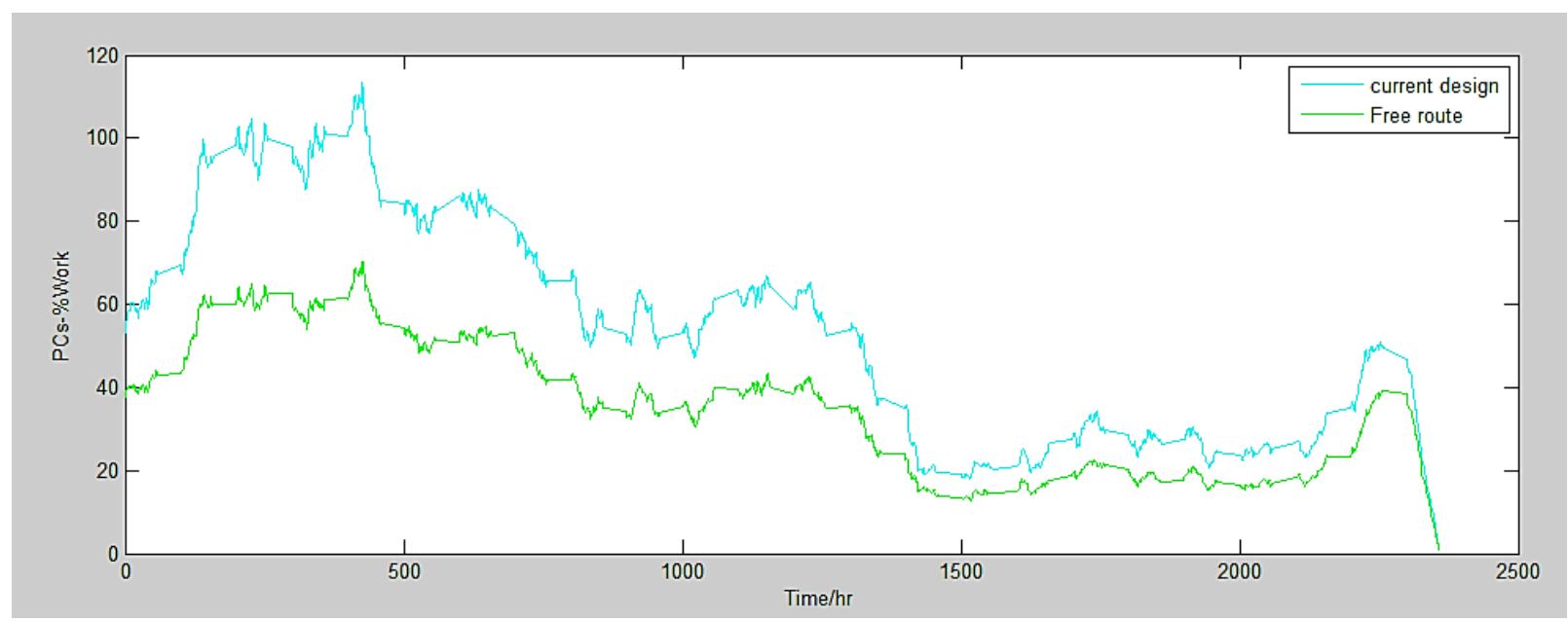

Fig. 9: Planning controllers workload relief

\section{Conclusion}

In this paper, the authors proposed the implementation of free route airspace in Manila FIR in order to increase the airspace capacity and efficiency in the Philippines. The aim of this study was to cater for the increasing number of aircraft in the airspace. The airspace utilization rate in the current discrete airway point structure was low. By implementing the free route airspace, there was an increase in capacity. Since pilots could plan the aircraft freely between the entry points and the exit points, there was a decrease in workload for ATCOs. Moreover, the advantages of changing from current route structure to free route structure included lower flight traveling time and decreased energy consumption. Free route structure could contribute significantly to curb climate change impact due to that greenhouse gas mostly comes from car emissions and aircraft emissions.

In general, this paper uses simulation to justify the benefit of implementing the free route airspace in Manila FIR.
The future work for this study could include the following:

1) Expand the justification of free route concept to other ASEAN FIRs.

2) Include more parameters to make the simulation closer to real scenarios.

\section{Acknowledgment}

This research was sponsored by the ATMRI of NTU and CAAS via ATMRI Project No. 2014-D2ZHONG for Regional Airspace Capacity Enhancement - ASEAN Pilot.

\section{References}

Barrett SD (2004). How do the demands for airport services differ between full-service carriers and low-cost carriers?. Journal of Air Transport Management, 10(1): 33-39.

Bicchi A and Pallottino L (2000). On optimal cooperative conflict resolution for air traffic management systems. IEEE Transactions on Intelligent Transportation Systems, 1(4): 221-231. 
DeSA UN (2013). World population prospects: The 2012 revision. Population Division of the Department of Economic and Social Affairs of the United Nations Secretariat, New York, USA

EUROCONTROL (2008). Free Route Airspace (FRA). European Organisation for the Safety of Air Navigation. Available online at: http://www.eurocontrol.int/articles/free-route-airspace

EUROCONTROL (2015). System for traffic assignment and analysis at a macroscopic level (SAAM). European Organisation for the Safety of Air Navigation. Available online at: http://www.eurocontrol.int/saam

Gibbs WW (1995). Free-for-all flights. Scientific American, 273(6): 34-37.

Han SC, Pei CG, Sui D, and Zuo L (2006). Security analysis of area navigation parallel airway [J]. Acta Aeronautica ET Astronautica Sinica, 27(6): 1023-1027.

Hart PE, Nilsson NJ, and Raphael B (1968). A formal basis for the heuristic determination of minimum cost paths. IEEE Transactions on Systems Science and Cybernetics, 4(2): 100 107.

Hering H (2005). Air traffic freeway system for Europe (EEC Note 20/05). Eurocontrol Experimental Centre, Brétigny-sur-Orge, France.

Paielli RA and Erzberger H (1997). Conflict probability estimation for free flight. Journal of Guidance, Control, and Dynamics, 20(3): 588-596.

Pappas G, Tomlin C, Lygeros J, Godbole D, and Sastry S (1997). A next generation architecture for air traffic management systems. In the $36^{\text {th }}$ IEEE Conference on Decision and Control,
IEEE, Piscataway, USA, 3: 2405-2410. https://doi.org/ 10.1109/CDC.1997.657516

Rekkas C and Rees M (2008). Towards ADS-B implementation in Europe. In the Tyrrhenian International Workshop on Digital Communications - Enhanced Surveillance of Aircraft and Vehicles (TIWDC/ESAV'08), IEEE, New Jersey, USA: 1-4. https://doi.org/10.1109/TIWDC.2008.4649019

RTCA (1995). Final report on free flight implementation. Radio Technical Commission for Aeronautics, Washington, USA.

Sunil E, Hoekstra J, Ellerbroek J, Bussink F, Vidosavljevic A, Delahaye D, and Aalmoes R (2016). The influence of traffic structure on airspace capacity. In the $7^{\text {th }}$ International Conference on Research in Air Transportation (ICRAT'16), Philadelphia, USA.

Tomlin C, Pappas G, Lygeros J, Godbole D, and Sastry S (1996). Hybrid control models of next generation air traffic management. In the International Hybrid Systems Workshop on Lecture Notes in Computer Science, Springer, Berlin, Germany, 1273: 378-404. http://doi.org/10.1007/ $\mathrm{BFb} 0031570$

Xie Z and Zhong ZW (2016). Aircraft path planning under adverse weather condition. In the $3^{\text {rd }}$ International Conference on Mechanics, Electronics and Automation Engineering (ICMEAE'16), EDP Sciences, Les Ulis, France. https://doi.org/10.1051/matecconf/20167715001

Xie Z and Zhong ZW (2016). Changi airport passenger volume forecasting based on an artificial neural network. In the Far East Journal of Electronics and Communications (ICACCI'16), Pushpa Publishing House, Cebu, Philippines, 2: 163-170. https://doi.org/10.17654/ECSV216163 